IN THE RED CROSS WORLD

\title{
SEVENTH REGIONAL MEETING OF ARAB RED CRESCENT AND RED CROSS SOCIETIES
}

This regional conference took place in Riyadh from 27 to 31 January 1975. Organized by the Saudi Arabian Red Crescent and chaired by its President, Dr. Abdul Aziz Al-Mudarres, it brought together delegates from the National Societies of Algeria, Bahrain, Egypt, Iraq, Jordan, Kuwait, Lebanon, Libya, Mauritania, Morocco, Saudi Arabia, Somalia, Southern Yemen, Sudan, Syria and Tunisia. Delegates of the "Palestinian Red Crescent" and of the Ministry of Health of the Arab Emirates took part in the meeting. The League was represented by its Secretary-General, Mr. H. Beer, accompanied by several League staff members. Also present, on behalf of the Study for the Re-appraisal of the Role of the Red Cross, was Mr. Warras and, for the ICRC, Mr. Gaillard and Mr. Hocké, Directors, and Mr. Convers, a delegate.

The conference was opened by the Minister of Labour and Social Affairs of Saudi Arabia, excerpts from whose speech are presented below:

The whole world is paying tribute and respect and full support to the great Red Crescent-Red Cross humanitarian .nission based on such fundamental principles of humanity, friendship and unity, rendering impartial assistance when and wherever needed indiscriminately.

Our world of today with all sorts of calamities and dangers threatening mankind is putting all hopes and wishes on this unique humanitarian institution, more than ever before, to alleviate and relieve man's distress during war and peace times and to promote peace.

The Red Cross and Red Crescent movement born on the battle field with the desire to give care and treatment to the victims of conflicts has expanded, as we see today, to cover all humanitarian fields during war and peace times alike, and distinguished itself as the hopeful resort for all victims.

When supporting and standing by this humanitarian movement we are matching ourselves with the supreme pioneer principles and teachings of the great Islam from where all our acts and moves are derived and inspired. We are dictated by our religion to be humane and to dedicate ourselves to 
the humanitarian work and peace and all our national and international commitments and initiatives are based on these ideals and principles.

Among the questions on the agenda were the following: an Arab institute for the training of volunteers; the establishment of a permanent secretariat for the Arab National Societies; the Second Session of the Diplomatic Conference in Geneva; the creation of new National Societies in the States of the Arab Gulf; the independence of National Societies; activities and proposals by the Henry Dunant Institute. Discussions also dealt with the activities of the ICRC in the Middle East, in the course of which Mr. Hocké had occasion to recall the bases of ICRC action in the occupied territories and to draw attention to the fact that the ICRC, even more than in the past, relies upon the support of the Arab Governments and National Societies.

The participants also considered problems relating to the diffusion of the Geneva Conventions. Mr. Gaillard described the activities of the ICRC in this connection, through translations and publications. A resolution was adopted by the conference, urging Governments and National Societies to intensify their activities in this field. The following is the text of the resolution:

The Seventh Conference of Arab National Societies, conscious of the need to continue and develop efforts for the diffusion of the Geneva Conventions,

asks all Arab National Societies to intervene with their respective Governments to assure that practical and effective measures are taken to:

teach systematically the essential provisions of the Geneva Conventions in the armed forces, down to the level of the ordinary soldier; in addition, to teach fundamental humanitarian principles to young people, particularly in the secondary schools;

also asks the National Societies to train personnel capable of teaching the Geneva Conventions;

requests the ICRC to continue its activities in this field by supporting, as necessary, the efforts of National Societies.

The participants agreed, finally, to hold the next Regional Conference at Damascus in 1976. The Conference will be organized by the Syrian Red Crescent. 